\title{
Understanding the public's role in reducing low-value care: a scoping review
}

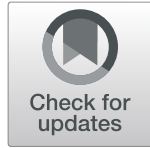

Emma E. Sypes ${ }^{1}$, Chloe de Grood ${ }^{1}$, Fiona M. Clement ${ }^{1,2}$, Jeanna Parsons Leigh ${ }^{3}$, Liam Whalen-Browne ${ }^{4}$, Henry T. Stelfox ${ }^{1,2,4}$ and Daniel J. Niven ${ }^{1,2,4^{*}}$

\begin{abstract}
Background: Low-value care initiatives are rapidly growing; however, it is not clear how members of the public should be involved. The objective of this scoping review was to systematically examine the literature describing public involvement in initatives to reduce low-value care.
\end{abstract}

Methods: Evidence sources included MEDLINE, EMBASE, and CINAHL databases from inception to November 26, 2019, grey literature (CADTH Tool), reference lists of included articles, and expert consultation. Citations were screened in duplicate and included if they referred to the public's perception and/or involvement in reducing lowvalue care. Public included patients or citizens without any advanced healthcare knowledge. Low-value care included medical tests or treatments that lack efficacy, have risks that exceed benefit, or are not cost-effective. Extracted data pertained to study characteristics, low-value practice, clinical setting, and level of public involvement (i.e., patient-clinician interaction, research, or policy-making).

Results: The 218 included citations were predominantly original research $(n=138,63 \%)$, published since $2010(n=$ $192,88 \%)$, originating from North America $(n=146,67 \%)$. Most citations focused on patient engagement within the patient-clinician interaction ( $n=156,72 \%)$, using tools that included shared decision-making $(n=66,42 \%)$ and patient-targeted educational materials $(n=72,46 \%)$, and reported both reductions in low-value care and improved patient perceptions regarding low-value care. Fewer citations examined public involvement in low-value care policy-making $(n=33,15 \%)$. Among citations that examined perspectives regarding public involvement in initiatives to reduce low-value care $(n=10,5 \%)$, there was consistent support for the utility of tools applied within the patient-clinician interaction and less consistent support for involvement in policy-making.

Conclusions: Efforts examining public involvement in low-value care concentrate within the patient-clinician interaction, wherein patient-oriented educational materials and shared decision-making tools have been commonly studied and are associated with reductions in low-value care. This contrasts with inclusion of the public in lowvalue care policy decisions wherein tools to promote engagement are less well-developed and involvement not consistently viewed as valuable.

Trial registration: Open Science Framework (https://osf.io/6fsxm)

Keywords: Low-value care, De-implementation, De-adoption, Patient engagement, Choosing wisely

\footnotetext{
* Correspondence: Daniel.Niven@albertahealthservices.ca

${ }^{1}$ Department of Community Health Sciences, Cumming School of Medicine, University of Calgary, Calgary, Canada

${ }^{2} \mathrm{O}^{\prime}$ Brien Institute of Public Health, Cumming School of Medicine, University of Calgary, Calgary, Canada

Full list of author information is available at the end of the article
}

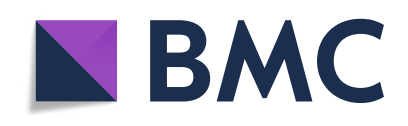

(- The Author(s). 2020 Open Access This article is licensed under a Creative Commons Attribution 4.0 International License, which permits use, sharing, adaptation, distribution and reproduction in any medium or format, as long as you give appropriate credit to the original author(s) and the source, provide a link to the Creative Commons licence, and indicate if changes were made. The images or other third party material in this article are included in the article's Creative Commons licence, unless indicated otherwise in a credit line to the material. If material is not included in the article's Creative Commons licence and your intended use is not permitted by statutory regulation or exceeds the permitted use, you will need to obtain permission directly from the copyright holder. To view a copy of this licence, visit http://creativecommons.org/licenses/by/4.0/. The Creative Commons Public Domain Dedication waiver (http://creativecommons.org/publicdomain/zero/1.0/) applies to the data made available in this article, unless otherwise stated in a credit line to the data. 


\section{Contributions to the literature}

- Low-value care initiatives are rapidly growing; however, it is not clear how members of the public should be involved.

- Our study identified that efforts examining public involvement in low-value care concentrate within the patient-clinician interaction, wherein patient-oriented educational materials and shared decision-making tools have been commonly studied and are associated with reductions in low-value care.

- Tools to promote inclusion of the public in low-value care policy decisions are less well-developed, and involvement is not consistently viewed as valuable.

\section{Background}

The ongoing use of low-value healthcare practices (i.e., low-value care), broadly defined as medical tests or treatments that lack efficacy, have risks that exceed benefit, or are not cost effective [1], impedes the delivery of safe, efficient, and cost-effective healthcare [2]. For patients and their caregivers, receiving a low-value test or treatment can lead to physical, psychological, and financial consequences [2-4]. Estimates suggest that unnecessary care in the USA costs upwards of $\$ 210$ billion dollars annually [5] and consumes resources that could be allocated to high-value, necessary care. Studies from Australia and the USA identified 156 [6] and 146 [7] low-value practices, respectively, and over 500 "Do Not Do" recommendations have been produced through the Choosing Wisely campaign [8]. In the UK, the National Institute for Health and Care Excellence (NICE) has included upwards of 1000 "Do Not Do" recommendations in their evidence-based guidelines for care in the $\mathrm{Na}$ tional Health Service (NHS) [9]. However, this identification of low-value practices has not been followed by a commensurate reduction in their use [10-12]. This is likely influenced by a number of factors [13], one of which may be challenges with engaging relevant stakeholders such as clinicians, decision makers, and the public.

Members of the public (e.g., patients, caregivers, and citizens) have been identified as important stakeholders within initiatives to reduce low-value care $[1,14,15]$. Their dual role in this process includes (1) payment for healthcare services directly or indirectly and (2) recipients of healthcare as patients. Thus, there are multiple opportunities for their inclusion in efforts to reduce lowvalue care. At its inception, the Choosing Wisely campaign recognized the patient-clinician interaction as an opportunity to reduce low-value care and developed patient-targeted educational materials to empower patients to engage with their clinicians in a joint effort to avoid selected low-value care practices [16]. Patient and public representatives may also contribute to research activities aiming to reduce low-value care, as numerous patient-targeted interventions continue to be developed and evaluated [17]. In addition, there has been a call for public involvement within healthcare policy and administration, with opportunities in health technology reassessment [18] and health system-level initiatives aiming to reduce low-value care $[1,19]$.

How patients and the public are optimally involved in initiatives to reduce low-value care has been highlighted as a deficiency in the science that underpins reducing low-value care $[15,20]$. While a number of reviews and editorials speak to engaging the public in reducing low-value care [1, 21-23], there is a poor understanding of which organizations and stakeholders should engage the public, the extent to which the public should be involved, and how public involvement impacts initiatives to reduce low-value care, and importantly, how members of the public themselves wish to be involved. Given these broad knowledge gaps, we used scoping review methodology to systematically examine the literature to further understand current strategies for public involvement in reducing low-value care and identify areas that require additional research. Scoping review methodology was selected as it provides the optimal approach to synthesizing and mapping evidence from a body of literature that is predicted to be large and heterogenous [24, 25].

\section{Methods}

\section{Overview and definitions}

Methods were guided by the Joanna Brigg's Institute Methodology for Scoping Reviews [24], and the protocol was registered with the Open Science Framework (https://osf.io/6fsxm). The Preferred Reporting Items for Systematic Reviews and Meta-Analyses extension for Scoping Reviews (PRISMA-ScR) checklist was used to guide reporting of methods and findings [25]. Operational definitions for the terms "low-value care," "public," and "public involvement" are presented in Table 1. Our operational definition for "low-value care" was based on that proposed by Elshaug et al. as a medical test or treatment "in which evidence suggests it confers no or very little benefit for patients, or risk of harm exceeds probable benefit, or, more broadly, the added costs of the intervention do not provide proportional added benefit" [1]. Although other definitions of low-value care exist, owing to a lack of consensus within the literature [17], we chose this definition because it is broad and encompasses three concepts commonly used when conceptualizing the value of care (i.e., cost, efficacy, and safety). 
Table 1 Operational definitions for key concepts

\begin{tabular}{lll}
\hline Term & Operational definition & Example \\
\hline $\begin{array}{ll}\text { Low-value } \\
\text { care }\end{array}$ & $\begin{array}{l}\text { Medical tests and treatments that meet one or more of the } \\
\text { following criteria: lack of efficacy, not cost-effective, or risks } \\
\text { exceeded benefit }\end{array}$ & Antibiotics for viral upper respiratory tract infections \\
Public & $\begin{array}{l}\text { Patients, caregivers, and potential patients without advanced } \\
\text { healthcare knowledge }\end{array}$ & A patient attending an appointment at a primary care clinic \\
& $\begin{array}{l}\text { Excludes clinicians (any front-line healthcare professional), } \\
\text { healthcare researchers, and healthcare administrators }\end{array}$ & \\
$\begin{array}{l}\text { Public } \\
\text { involvement }\end{array}$ & $\begin{array}{l}\text { The engagement of members of the public in an initiative } \\
\text { aiming to reduce low-value care }\end{array}$ & $\begin{array}{l}\text { Engaging a patient in shared decision-making to explore their prefer- } \\
\text { ences and the potential risks and benefits to a low-value diagnostic } \\
\text { imaging test }\end{array}$ \\
\hline
\end{tabular}

\section{Data sources and searches}

We searched MEDLINE, EMBASE, and CINAHL databases from inception to November 26, 2019. The initial search was conducted on June 28, 2018, then updated on November 26, 2019. The search strategy (Additional file 1) was developed in consultation with a medical librarian and was peer reviewed by a second medical librarian using the Peer Review of Electronic Search Strategies (PRESS) checklist [26]. Search terms included keywords and their synonyms relevant to three main concepts: low-value care, the public, and public involvement. Recognizing that terminology may be nuanced, low-value care literature was identified using the most commonly cited terminology within contemporary scientific literature (e.g., de-adoption, overuse, and deimplementation) $[27,28]$. The search terms were inclusive of all common terms identified in a prior scoping review of the literature [27]. These intentionally broad search terms acknowledge the absence of a universally agreed-upon taxonomy of terms that refer to low-value care and established medical subject heading terms to identify low-value care articles. The database search was limited to English as much of the terminology pertaining to low-value care (e.g., Choosing Wisely, low value, and overuse) is language-specific and may not translate well across languages. Given the broad nature of the research question, there was no limitation of the search strategy based on the study design. Additional citations were identified by searching the grey literature using the Canadian Agency for Drugs and Technologies in Health (CADTH) tool [29] (Additional file 2), reference lists of included articles, and consultation with experts in the field.

\section{Citation selection and screening}

Citations were eligible for inclusion if they were written in English and referred to the public's perception of and/ or direct involvement in reducing low-value care. All study designs were eligible for inclusion. Citations were excluded if they predominantly focused on cliniciantargeted strategies for reducing low-value care (e.g., personalized audit and feedback data). Eligible citations were screened independently in two steps by two investigators using Endnote (Clarivate Analytics, Philadelphia, USA). Prior to screening, the citation screening form was pilot tested using a random sample of 50 citations. The form was refined until agreement was consistent as denoted by a kappa statistic $(k)>0.8$. During level one screening, both investigators examined the title and abstract of each citation to determine its eligibility for full text review. Citations that met the eligibility criteria or were unclear proceeded to level two screening, where both investigators reviewed the full text of each citation to determine eligibility. If the citation was excluded, the precise reason for exclusion was recorded. For citations without abstracts, the title was used to assess for eligibility at title/abstract screening, and if the title appeared relevant, the citation proceeded to full-text screening. Reference lists of included articles were screened in a similar fashion, first, by title and then by full text both independently and in duplicate. Any disagreements were resolved through discussion or consultation with another author (DJN). Agreement during both phases of screening was quantified using the kappa statistic [30].

\section{Data extraction}

All data extraction was conducted independently by two investigators using DistillerSR (Evidence Partners, Ottawa, Canada). We used a conceptual framework to guide data extraction (Table 2). Prior to full data extraction, our data extraction form was pilot tested using six randomly selected citations. Extracted data broadly pertained to study characteristics (e.g., year, country, and study design), the low-value practice of interest (i.e., diagnostic test or therapeutic treatment), and the clinical setting (e.g., emergency department and primary care). We mapped included citations to our conceptual framework (Table 2) to capture the phase of deimplementation in which the public was involved (e.g., identifying and prioritizing low-value practices for deimplementation) and extracted additional data to provide further detail about how and where the public was 
Table 2 Conceptual framework for data extraction

\begin{tabular}{lll}
\hline Phase of de-implementation $^{\text {a }}$ & Operational definition & Example \\
\hline $\begin{array}{ll}\text { Identify and prioritize low-value } \\
\text { clinical practices }\end{array}$ & $\begin{array}{l}\text { 1) The public's conceptual understanding of low-value } \\
\text { care }\end{array}$ & $\begin{array}{l}\text { 1) A survey asking members of the public to describe } \\
\text { low-value care }\end{array}$ \\
& $\begin{array}{l}\text { 2) The public's involvement in identifying or prioritizing } \\
\text { lowlue practices for de-implementation }\end{array}$ & $\begin{array}{l}\text { 2) Patient and provider co-creation of a priority list of } \\
\text { practices for de-implementation }\end{array}$ \\
$\begin{array}{ll}\text { Assess barriers and facilitators to } \\
\text { de-implementation }\end{array}$ & $\begin{array}{l}\text { The public's perception of barriers and facilitators to } \\
\text { reducing low-value care }\end{array}$ & $\begin{array}{l}\text { Exploring patient perspectives on the demand for low- } \\
\text { value care }\end{array}$ \\
$\begin{array}{ll}\text { Select, tailor, and implement de- } \\
\text { implementation intervention }\end{array}$ & $\begin{array}{l}\text { Public involvement in developing interventions to } \\
\text { reduce low-value care }\end{array}$ & $\begin{array}{l}\text { Involving a patient representative in the design of an } \\
\text { intervention to reduce a low-value practice }\end{array}$ \\
$\begin{array}{ll}\text { Evaluate de-implementation } \\
\text { process and outcomes }\end{array}$ & $\begin{array}{l}\text { The public's involvement in the evaluation of } \\
\text { outcomes of an initiative to reduce low-value care }\end{array}$ & $\begin{array}{l}\text { Inclusion of patient-reported outcomes in an interven- } \\
\text { tion to reduce the use of a low-value practice }\end{array}$
\end{tabular}

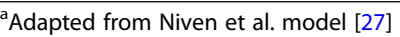

involved in reducing low-value care. To understand how the public was involved, we extracted data that described how the public was engaged in an initiative to reduce low-value care (e.g., shared decision-making). This is referred to as the "strategy for public involvement." To understand where the public was involved, we categorized each citation by the "level of patient engagement," which included the "patient-clinician interaction" (i.e., strategies for public involvement that were employed during a clinical interaction), "research" (i.e., involving the public in conducting or evaluating research aiming to reduce low-value care), or "policy/administration" (i.e., involving the public in policy or administration level initiatives to reduce low-value care). Because this was a scoping review wherein a large number of heterogeneous citations was expected and desired, quality assessment of included citations was felt to be unlikely to yield the kind of useful information that it would for a more focused systematic review; thus, in accord with the PRISMA extension for scoping reviews, quality assessment of included citations was not performed [25].

\section{Data synthesis and analysis}

Included citations were mapped to a conceptual framework to describe how the public was engaged in reducing low-value care (Table 2). The framework was developed by determining which components of a conceptual framework for facilitating de-implementation were most relevant to public involvement [27]. Included citations that described or evaluated a strategy for public involvement were assessed to determine whether they indicated support or did not support the given strategy. For original research citations (e.g., randomized clinical trial), a statistically significant reduction in the targeted low-value aspect of care indicated support for the given public involvement strategy. For non-original research citations, (e.g., editorial) support was indicated by a generally positive discussion of the given strategy within the citation. All data was summarized by numerical counts and percentages as appropriate using the Stata statistical software (StataCorp, TX, USA).

\section{Results}

\section{Citation selection}

Searches yielded 9548 citations from electronic databases and 31 citations from the grey literature (Fig. 1). After removing duplicates, 6736 unique citations were screened for inclusion from which 395 proceeded to full-text screening, and 182 were included in the review. The most common reasons for excluding citations during full-text screening were lack of focus on reducing a low-value practice and focus on other stakeholders such as physicians. Screening reference lists of included citations and consultation with experts identified an additional 36 citations which were included in the final review. Combined with the 182 citations, the final review included 218 citations. Most included citations derived from electronic databases $(n=160)$, followed by reference list/expert consultation $(n=36)$ and grey literature $(\mathrm{n}=22)$.

\section{Study characteristics and classification within conceptual frameworks}

A detailed bibliography of included citations is available in Additional file 3, and an overall summary of relevant characteristics is presented in Table 3. Included citations were predominantly original research ( $n=138,63 \%)$ from North America $(n=146,67 \%)$. Most citations were published in the last 10 years $(n$ $=192,88 \%$ ), with a large increase following 2012/ 2013 (Fig. 2). Among citations reporting original research, most were observational studies $(n=34,16 \%)$, qualitative designs $(n=28,13 \%)$, or randomized clinical trials $(n=21,10 \%)$. Other article types included narrative reviews $(n=34,16 \%)$, commentaries $(n=$ $34,16 \%$ ), and website items (e.g., medical society websites and health technology assessment websites) $(n=10,5 \%)$. Most citations spoke of low-value care in a general sense $(n=95,43 \%)$, with $32 \%(n=69)$ focusing on low-value treatments and 17\% $(n=38)$ on low-value tests. Among citations that reported reducing low-value care within a specific clinical setting, the most common location was within inpatient 


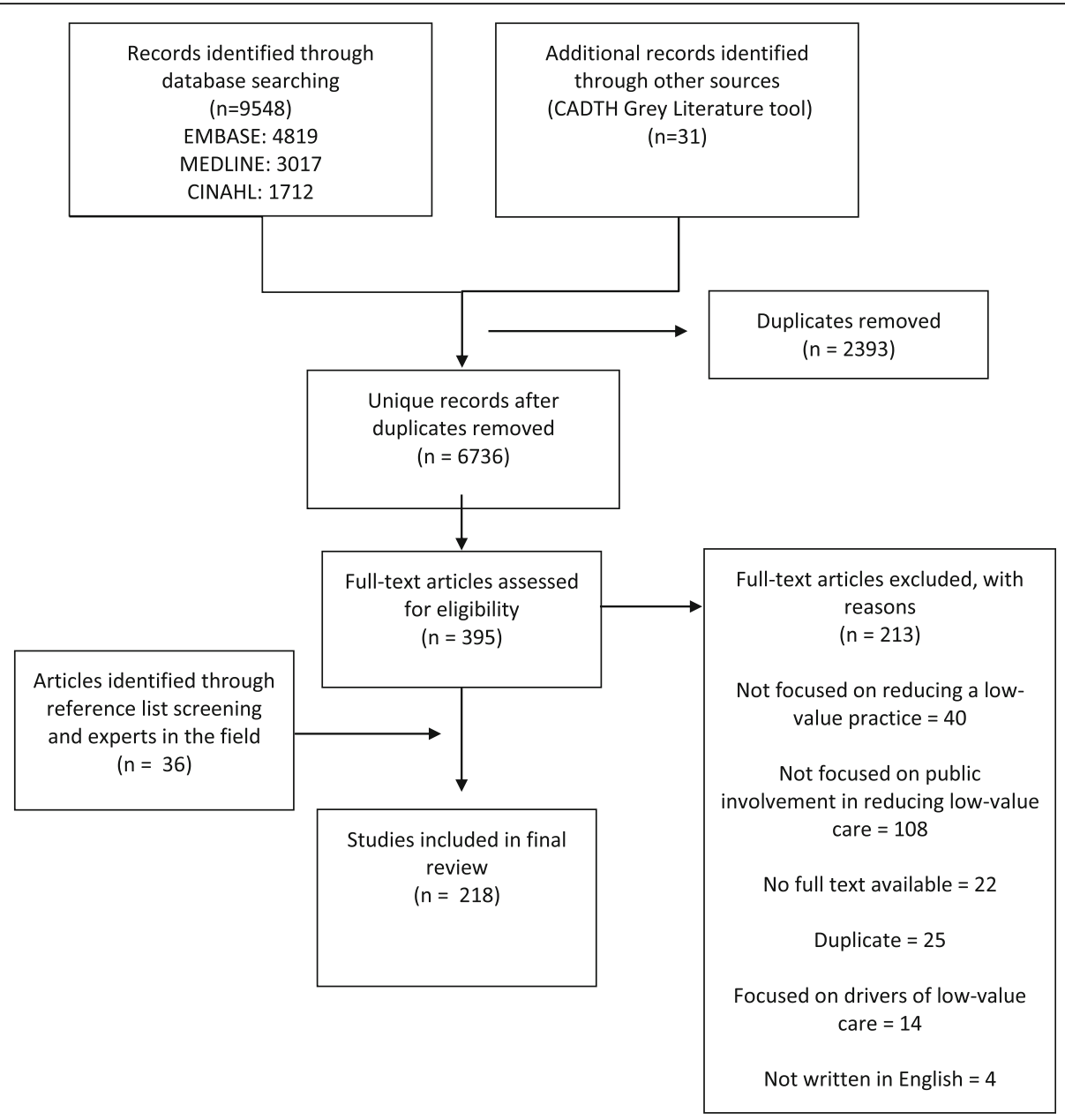

Fig. 1 Selection of studies included in the review

hospital departments $(n=42,19 \%)$, followed by primary care practices $(n=35,16 \%)$ and the community $(n=28,13 \%)$.

\section{Inclusion of the public in strategies that aim to reduce low-value care}

Strategies for public involvement in reducing low-value care were described or tested in 209 citations. Of these, 128 (61\%) were original research, and 80 (38\%) were non-original research. Most citations were referred to a strategy that engaged patients within the setting of a patient-clinician interaction $(n=148,71 \%)$. A smaller number addressed inclusion of the public in policy/administrative decision-making $(n=31,15 \%)$ or low-value care research $(n=56,27 \%)$ (Fig. 3). Examples of common strategies for public involvement across all three levels of engagement and within their respective components of the conceptual framework for reducing lowvalue care are displayed in Fig. 4. At the patient-clinician interaction level, the focus was on helping patients identify low-value practices through the dissemination of educational materials and approaches such as shared decision-making (individual study details in Additional file 3). As depicted in Fig. 4, the significance of outcomes and/or discussion within these citations mostly indicated support for the utility of these strategies in reducing low-value care ("support" fully defined in the "Data Synthesis and Analysis" section). Of the 66 studies that focused on shared decision-making, 60 (91\%) supported that tool as a means of engaging patients in reducing low-value care, of which 24 (40\%) were original research. In studies that tested a shared decision-making approach, many reported improved patient knowledge and satisfaction with their decision-making process. In four studies (6\%), it was unclear whether support for the given patient engagement strategy was positive or negative. Two studies (3\%) did not support shared decisionmaking as a strategy for public engagement; however, these studies were both non-original research (website and narrative review). Of the 73 studies that discussed or evaluated providing educational materials as a strategy for public involvement, six (8\%) did not comment 
Table 3 Characteristics of included citations $(n=218)$

\begin{tabular}{|c|c|}
\hline Characteristic & $N(\%)$ \\
\hline \multicolumn{2}{|l|}{ Year of publication } \\
\hline 1980-1999 & $3(1.4)$ \\
\hline 2000-2009 & $23(10.5)$ \\
\hline 2010-2019 & $192(88.1)$ \\
\hline \multicolumn{2}{|l|}{ Continent of origin } \\
\hline North America & $146(66.7)$ \\
\hline Europe & $41(18.7)$ \\
\hline Australia & $20(9.2)$ \\
\hline Asia & $8(3.7)$ \\
\hline Africa & $1(0.5)$ \\
\hline South America & $1(0.5)$ \\
\hline Oceania & $1(0.5)$ \\
\hline \multicolumn{2}{|l|}{ Type of article } \\
\hline Original Research & $138(63.3)$ \\
\hline Observational ${ }^{\mathrm{a}}$ & $34(15.5)$ \\
\hline Qualitative & $28(12.8)$ \\
\hline Randomized controlled trials & $21(9.6)$ \\
\hline Non-randomized experimental & $13(5.9)$ \\
\hline Knowledge synthesis & $12(5.5)$ \\
\hline Consensus method & $11(5.0)$ \\
\hline Mixed methods & $8(3.7)$ \\
\hline Community jury & $8(3.7)$ \\
\hline Other ${ }^{b}$ & $3(1.7)$ \\
\hline Non-original research & $80(36.5)$ \\
\hline Narrative review & $34(15.5)$ \\
\hline Editorial/commentary & $34(15.5)$ \\
\hline Website items & $10(4.5)$ \\
\hline Policy report & $2(0.9)$ \\
\hline \multicolumn{2}{|l|}{ Type of low-value care } \\
\hline Low-value care in general & $95(43.4)$ \\
\hline Specific low-value practice(s) & $124(56.6)$ \\
\hline Test & $38(17.4)$ \\
\hline Treatment & $69(31.5)$ \\
\hline Both & $16(7.3)$ \\
\hline \multicolumn{2}{|l|}{ Clinical setting } \\
\hline Hospital & $42(19.2)$ \\
\hline Primary care & $35(16.0)$ \\
\hline Emergency Department & $22(10.0)$ \\
\hline Community $^{c}$ & $27(12.4)$ \\
\hline Not specified & $92(42.0)$ \\
\hline \multicolumn{2}{|l|}{ Level of public engagement $^{d}$} \\
\hline Patient interaction & $156(71.6)$ \\
\hline Research & $56(25.7)$ \\
\hline Policy/administration & $33(15.1)$ \\
\hline
\end{tabular}

ancludes cohort, cross-sectional, and case-control studies

bIncludes one case report and two public health outreach studies

Includes outpatient clinics, long-term care homes, dentistry, and

community pharmacies

${ }^{\mathrm{d}}$ Describes where public involvement occurred. Clinical interaction: strategies for public involvement that were employed during a clinical interaction such as a primary care visit; research: involving the public in conducting or evaluating research aiming to reduce low-value care such as patient-reported outcomes; policy/administration: involving the public in policy or administration level initiatives to reduce low-value care, such as prioritizing practices for disinvestment

on support for the strategy and three did not support the strategy (4\%). Of the 64 remaining articles that did indicate support, 36 (56\%) were original research, and 28 (44\%) were non-original research (Fig. 5).

With regard to public involvement in policy-making relevant to low-value care, 28 of 31 (90\%) citations referenced public involvement in identifying and prioritizing low-value practices, such as through the involvement of citizens in disinvestment decisions. Of these studies, most were original research $(n=20,71 \%)$ and involved the public through surveys, focus groups, and community engagement events to solicit their perspective about de-implementation decisions. Fewer studies involved the public in assessing barriers and facilitators to reducing a low-value practice $(n=2,6 \%)$ or in helping to develop an intervention to reduce a low-value practice $(n=5$, 15\%) (Fig. 3).

Within research activities, the public was engaged within all steps in our conceptual framework, from identifying and prioritizing low-value practices $(n=$ 37, 66\%) (e.g., involving patients in developing a Choosing Wisely list) to evaluating outcomes in interventions that aimed to reduce their use $(n=23,41 \%)$ (e.g., evaluating patient satisfaction with care and decision-making process) (Fig. 3). Here, studies commonly engaged the public in the development of educational materials or other patient-targeted tools used within interventions so that they would be clear and effective for patient use.

Stakeholder perceptions regarding public engagement in reducing low-value care

Ten citations examined stakeholder perspectives regarding public involvement in reducing low-value care (Table 4). Of these, five engaged demand-side stakeholders, including patients and other members of the public. The most commonly discussed strategy for public involvement was shared decision-making with care providers ( $n=4$ citations), wherein demand-side stakeholders unanimously agreed on its utility. One study from the UK asked community members if they thought citizens should be involved in disinvestment decision-making (i.e., the decision to withdraw resources from a given medical practice [41]) within the NHS, and the responses were overall negative [33]. In 


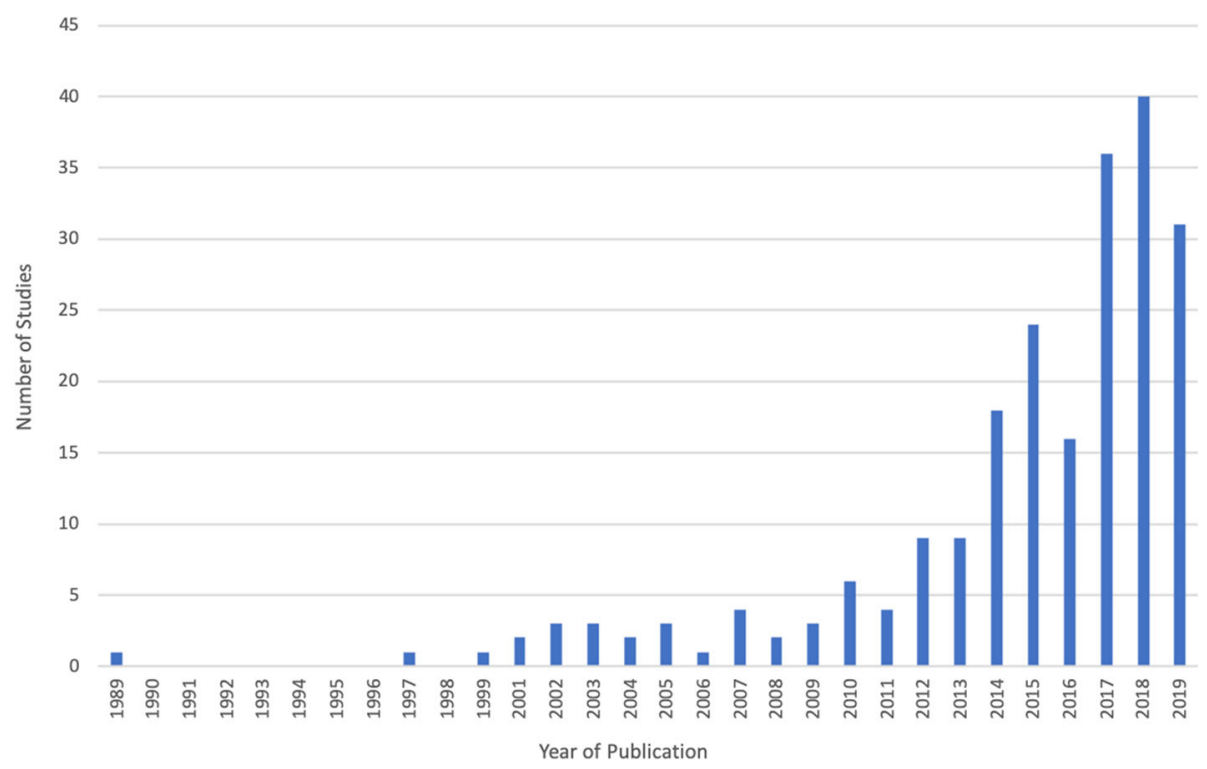

Fig. 2 Year of publication of included studies $(n=218)$

this study, community members felt as though citizens may not have the knowledge and expertise required to participate in disinvestment decision-making [33]. Another study from the UK posed the same question to healthcare administrators and found that while they were supportive of involving citizens, there were concerns about how to achieve meaningful engagement and the potential challenges that may arise [36]. Among the studies that engaged supply-side stakeholders, including physicians, nurses, and administrators, suggestions for public involvement that were supported included providing education about lowvalue practices [37, 38] and shared decision-making between care providers [37].

\section{Discussion}

We identified a large number of citations that described, evaluated, or suggested a strategy for public involvement in reducing low-value care. The majority of included citations were published following inception of Choosing Wisely in 2012 [42]. Current literature suggests that public involvement in reducing low-value care takes

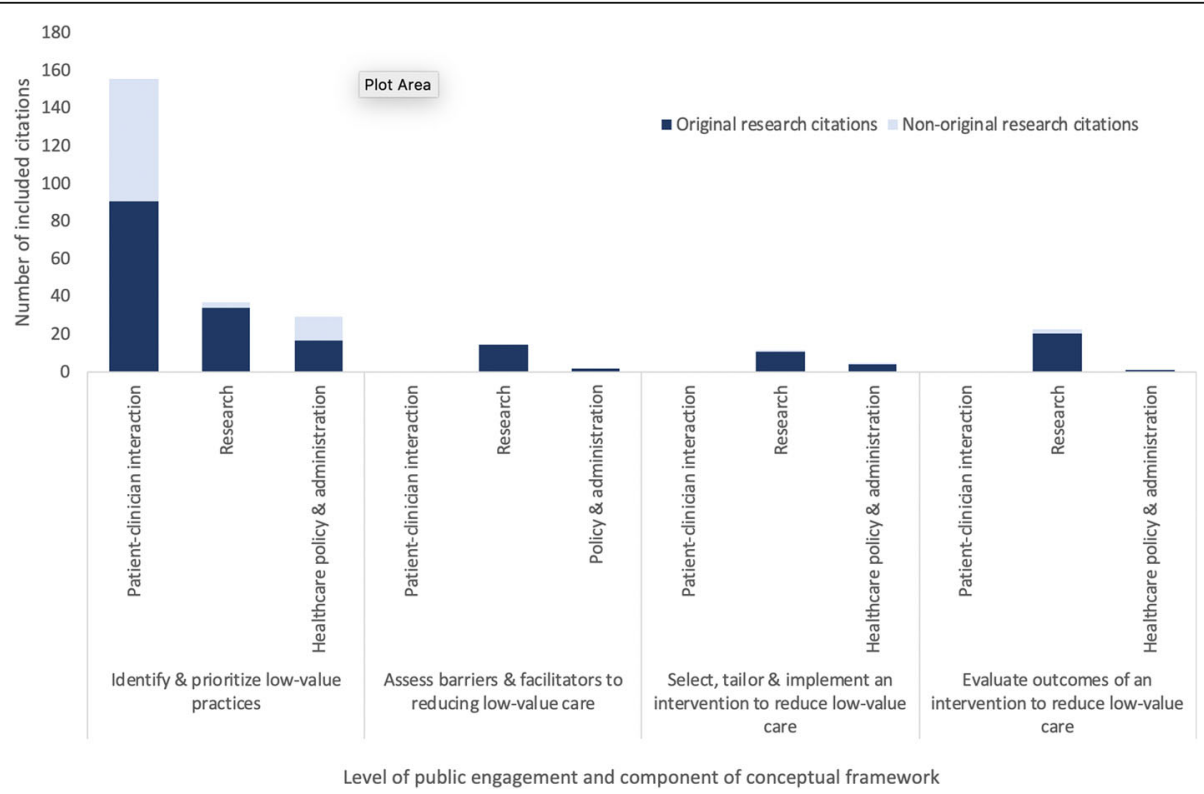

Fig. 3 Classification of included studies $(n=218)$ according to level of public engagement and main components of the conceptual framework 


\begin{tabular}{|c|c|c|c|c|c|}
\hline & & \multicolumn{4}{|c|}{ Component of conceptual framework for reducing low-value care } \\
\hline & & $\begin{array}{l}\text { Identify \& prioritize low- } \\
\text { value practices }\end{array}$ & $\begin{array}{l}\text { Assess barriers \& } \\
\text { facilitators to reducing } \\
\text { low-value care }\end{array}$ & $\begin{array}{c}\text { Select, tailor \& } \\
\text { implement intervention } \\
\text { to reduce low-value care }\end{array}$ & $\begin{array}{l}\text { Evaluate outcomes of an } \\
\text { intervention to reduce } \\
\text { low-value care }\end{array}$ \\
\hline \multirow{3}{*}{ 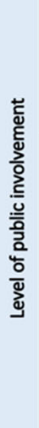 } & $\begin{array}{l}\text { Patient-clinician } \\
\text { interaction }\end{array}$ & $\begin{array}{l}\text { Shared-decision making } \\
\text { Patient education } \\
\text { materials }\end{array}$ & $\mathrm{n} / \mathrm{a}$ & $\mathrm{n} / \mathrm{a}$ & $\mathrm{n} / \mathrm{a}$ \\
\hline & Research & $\begin{array}{l}\text { Delphi process to } \\
\text { prioritize a list of low- } \\
\text { value practices that } \\
\text { involves a patient } \\
\text { representative }\end{array}$ & $\begin{array}{l}\text { Focus groups with } \\
\text { patients and caregivers } \\
\text { to explore barriers and } \\
\text { facilitators to reducing a } \\
\text { low-value practice }\end{array}$ & $\begin{array}{l}\text { Patient representative } \\
\text { involved with the design } \\
\text { of an intervention to } \\
\text { reduce a low-value } \\
\text { practice }\end{array}$ & $\begin{array}{l}\text { Patient reported } \\
\text { outcomes in an } \\
\text { intervention to reduce a } \\
\text { low-value practice }\end{array}$ \\
\hline & $\begin{array}{l}\text { Healthcare policy \& } \\
\text { administration }\end{array}$ & $\begin{array}{l}\text { Involving citizens in } \\
\text { disinvestment decisions }\end{array}$ & $\begin{array}{l}\text { Asking community } \\
\text { members about the } \\
\text { barriers and facilitators } \\
\text { to disinvestment }\end{array}$ & $\begin{array}{l}\text { Involving patient } \\
\text { advisors in the } \\
\text { implementation of CW } \\
\text { recommendations within } \\
\text { a hospital }\end{array}$ & $\mathrm{n} / \mathrm{a}$ \\
\hline
\end{tabular}

Fig. 4 Strategies for public involvement in reducing low-value care identified from included citations, according to level of engagement and main components of the conceptual framework

place across three levels: (1) patient-clinician interactions, (2) policy/administrative decision-making, and (3) research. Most citations focused on the patient-clinician interaction. Patient-targeted educational tools and shared decision-making were commonly described or tested strategies that demonstrated utility in reducing low-value care and were supported by effected stakeholders. In policy-making and healthcare administration regarding low-value care, the most commonly cited role for the public was providing input on the prioritization of practices for de-implementation. However, the perceived utility of public involvement in these circumstances was questioned by both the public and healthcare administrators. Within low-value care research, examples of public involvement included developing patient-targeted tools to be used in deimplementation interventions and being a public representative in projects to reduce low-value care. Given the breadth of the literature examined, the importance of public inclusion as stakeholders in de-implementation science initiatives [15] and resources dedicated to reducing low-value care [23], the findings of this study have implications for current and future initiatives that seek to reduce low-value care.

Arguably, the most important interaction in healthcare is that between the patient and the clinician. Therefore, it is not surprising that this was the most commonly described context for engaging the public in reducing low-

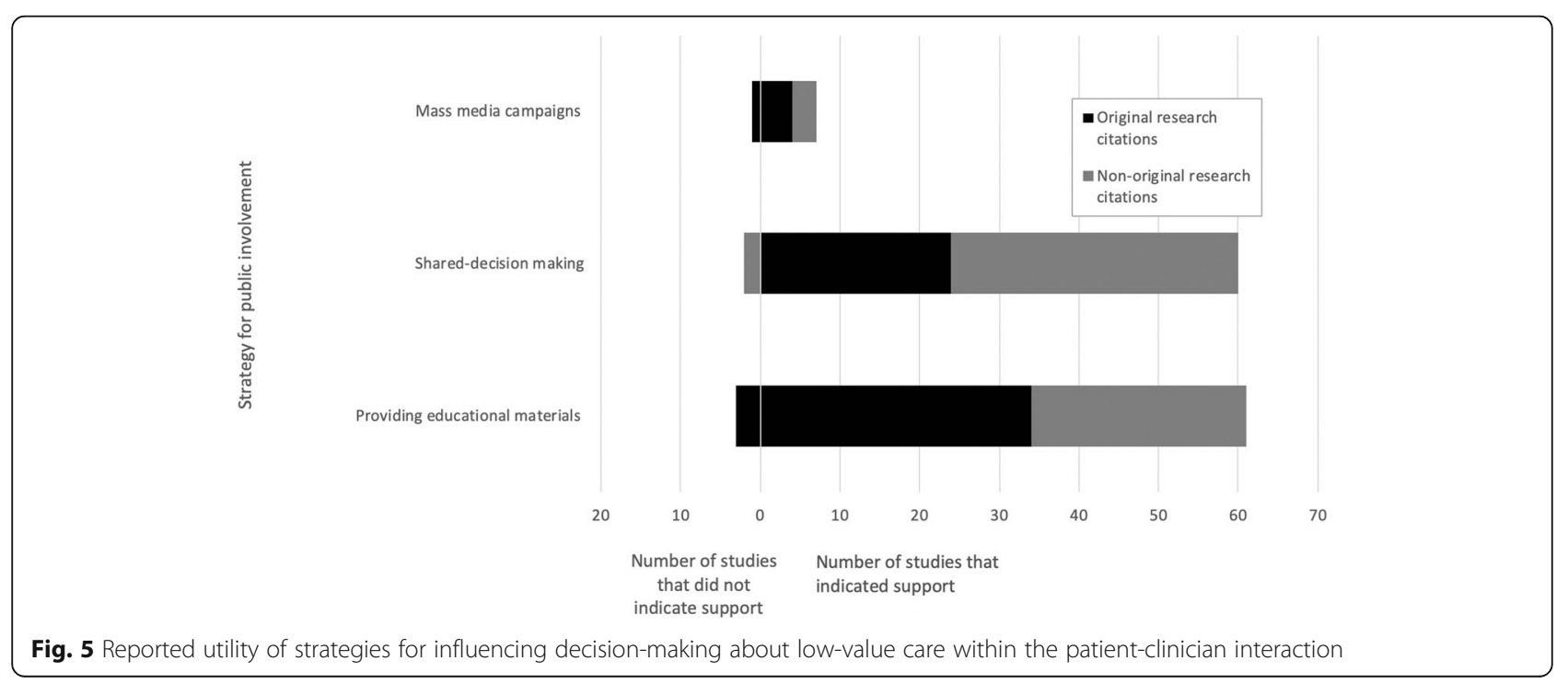



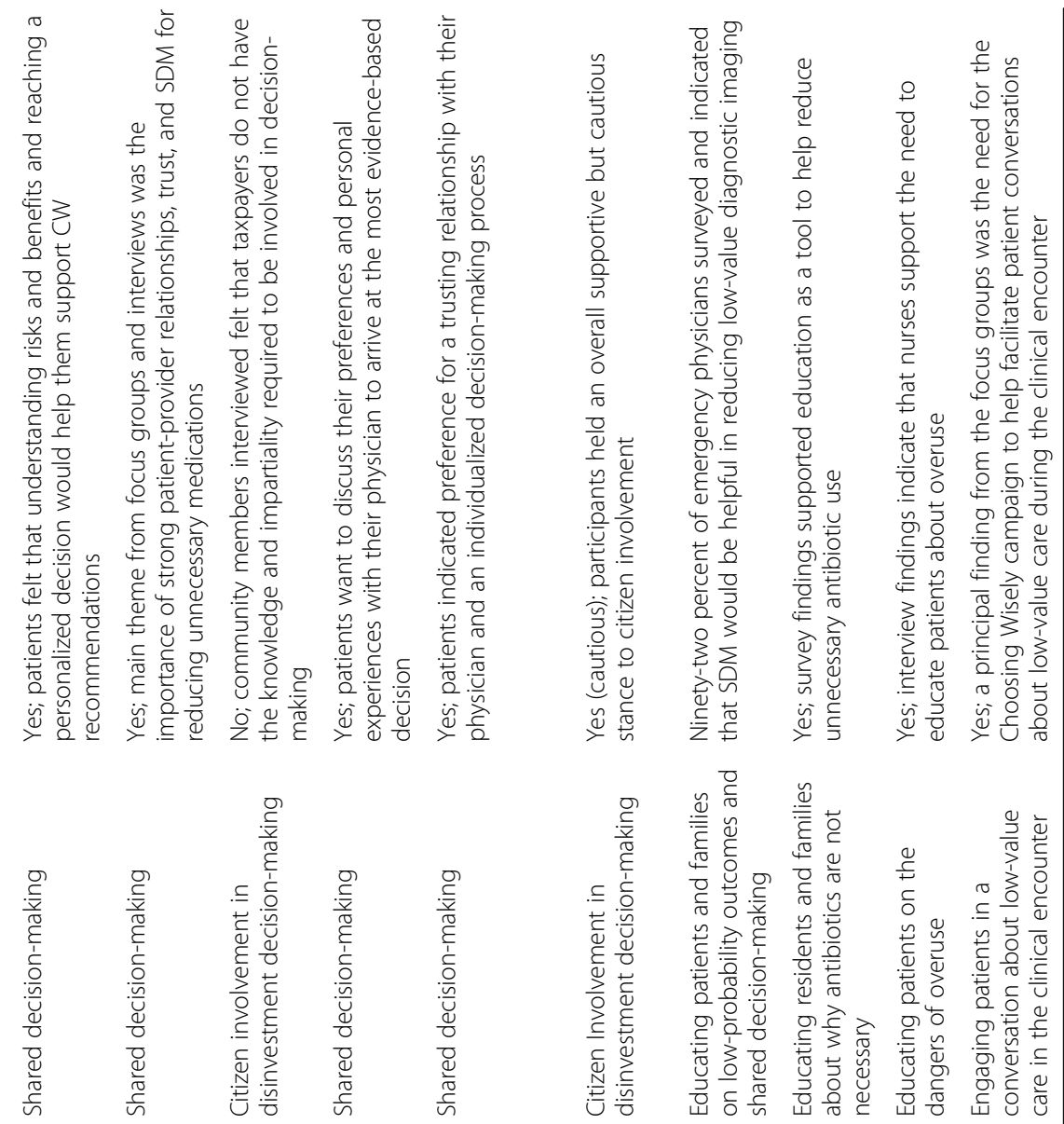

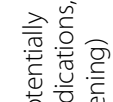

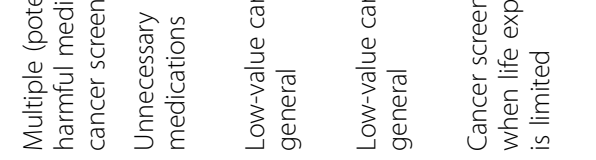

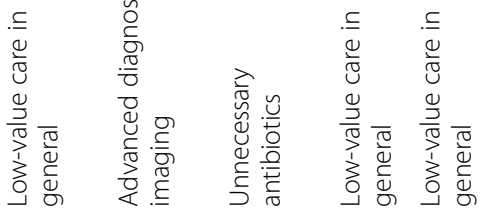

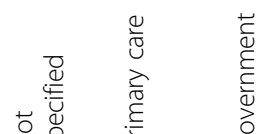

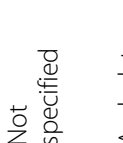

辛

है

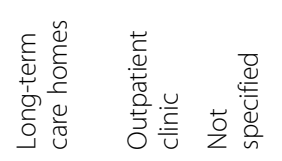

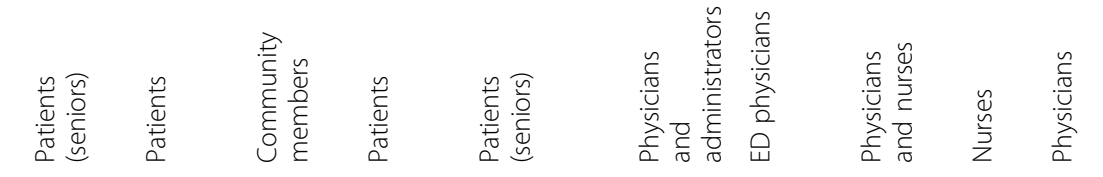

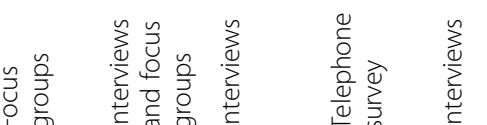

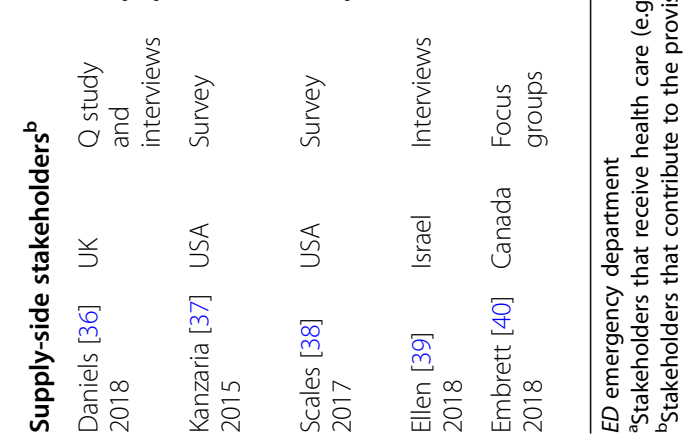


value care. Given that patient demand is a frequently cited barrier to reducing low-value care [15, 43-45], tools that inform patients and their caregivers at the point of care about the lack of utility of certain tests or treatments are promising. Commonly cited tools in current literature include educational materials, shared decision-making, and decision aids. The two studies that evaluated Choosing Wisely educational materials found them to improve general awareness and promote conversations about low-value practices [46, 47]. Comparatively, shared decision-making and decision aids, whose purpose is to guide a choice, are predicted to have a greater effect on changing practice [48]. In shared decision-making, patients and clinicians have a focused, detailed discussion pertinent to the low-value practice in question, thereby enabling patients to develop fully informed preferences [49]. Engaging in decision-making with clinicians can help foster a more trusting relationship, which in turn helps patients accept evidence-based recommendations and improve communication with clinicians $[32,35,50]$. We found that many of the studies that evaluated decision-making tools generally reported an associated reduction in use of the targeted low-value practice. Moreover, the small group of studies that examined the perspectives of patients, caregivers, and clinicians regarding the use of these tools reported that they support their use. Yet, shared decision-making is underused in clinical practice [51-53], likely due to the time and resources required in order for it to be effective [54]. Embracing shared decision-making as a strategy for reducing low-value care will require appropriate infrastructure within the healthcare system and cultural shift among patients and clinicians; however, as highlighted in a recent commentary on the complexities of deimplementation [15], taking such measures to address patient-level factors that affect de-implementation will be the key to the success of future de-implementation initiatives.

Our study identified two additional areas for public involvement in reducing low-value care-policy/administrative decision-making and research. At the policy level, members of the public have most commonly been involved in prioritizing low-value practices through community juries and citizen's councils. For example, Australia has hosted community juries to examine the public's perception about disinvestment for assisted reproductive technologies [55] and folate pathology testing [56]. The rationale for involving the public at this level is to gain their insight and perspectives to supplement those of administrators and policy makers [57, 58]. However, in contrast to the patient-clinician interaction where stakeholders unanimously agreed on the value of patient-targeted tools to reduce low-value care, stakeholders are uncertain about whether members of the public should be involved in policy-making and healthcare administration decisions surrounding low-value care. Recognizing that opportunities for public involvement in policy may be shaped by the country, level of government or institution, and nature of the low-value practice in question, this is an aspect of reducing lowvalue care that requires additional research. Within lowvalue care research, the public has contributed to the assessment of barriers and facilitators to reducing lowvalue care, developing and testing tools and interventions for reducing low-value care, and evaluating outcomes of interventions to reduce low-value care through the reporting of important patient-centred outcomes. These studies have acknowledged that involving the public in research can bring meaningful insight and increase the effectiveness of patient-targeted tools and interventions $[59,60]$. However, since few studies explain the rationale for or influence of public engagement in low-value care research, it is challenging to make conclusions about the impact of this involvement. Additionally, we did not identify any studies that examined stakeholder perspectives about involving patients as partners in low-value care research. Research that aims to explore how to successfully reduce low-value care will inform the implementation of initiatives at the administrative and policy level, which have the potential to create change on the largest scale. For this reason, understanding how to effectively engage patients and the public early on in the research process is imperative to the development of successful initiatives to reduce lowvalue care.

The findings of this scoping review must be interpreted within the context of its limitations. First, it is possible that in spite of being peer reviewed and rigorously developed by medical librarians, our electronic database searches may have missed relevant citations. This is potentially due to (1) restriction of the search to the English language and (2) lack of Medical Subject Heading $(\mathrm{MeSH})$ terms to identify low-value care literature that forced the use of a large number of key synonyms and related terms. Restriction to the English language was done because much of the terminology pertaining to low-value care (e.g., low-value, overuse, and de-implementation) is language-specific and may not translate well across languages. Low-value care synonyms and related terms derived from other contemporary literature reviews provided a comprehensive list of terms to include in the electronic database search [27]. It is possible that in combination with terms used to capture "public" and "public involvement," our search obtained a disproportionate number of citations focused on the patient-clinician interaction, with fewer citations focused on public involvement within policy and research settings. However, given that our final review 
included 218 citations, of which 31 and 56 focused on policy and research contexts, respectively, it is unlikely that our decision to restrict the search to the English language literature and search term selection missed a sufficiently large number of citations so as to alter our main results. Future evidence syntheses could use our work as a launching point to focus on public involvement in reducing low-value care within the policy and research contexts. Second, mapping included studies to our conceptual framework was a potentially subjective process at risk for misclassification bias. To minimize this risk, all studies were classified in duplicate, agreement checked, and disagreements resolved by consensus or consultation with a third reviewer. Finally, as this was a scoping review, we did not assess the quality of included articles. As described in the recently published PRISMA extension for scoping reviews, article quality assessment is not a typical feature of scoping reviews unless it aligns with the objectives of the review and is practical to complete [25]. The number and heterogeneity of included citations precluded any meaningful assessment of quality of included articles, nor would such data have materially changed the main results of the study.

\section{Conclusions}

In conclusion, there is a large body of literature examining public involvement in reducing low-value care. Current literature suggests that patients and caregivers should be engaged in initiatives to reduce low-value care through point-of-care strategies that include patienttargeted educational materials and shared decisionmaking tools. As shared decision-making is currently reported to be underused in clinical practice, use of shared decision-making to facilitate de-implementation of lowvalue care is likely to require additional infrastructure within the healthcare system and a cultural shift among patients and clinicians. In contrast, the perceived utility of public involvement in policy-making and healthcare administration regarding low-value care was questioned by both the public and healthcare administrators. Thus, there is a need to further understand the public's role in these contexts. As initiatives to reduce low-value care evolve, additional research should examine stakeholder perspectives and quantify the impact of public involvement on reducing low-value care.

\section{Supplementary information}

Supplementary information accompanies this paper at https://doi.org/10. 1186/s13012-020-00986-0.

Additional file 1. MEDLINE search strategy. Complete search strategy used for MEDLINE database.
Additional file 2. Information sources accessed through the Canadian Agency for Drugs and Technologies in Health (CADTH) Grey Literature Search Tool. List of relevan data sources accessed through the CADTH tool.

Additional file 3. Characteristics of citations included in the review $(n=$ 218). Bibliographic table of included studies.

\section{Abbreviations}

CADTH: Canadian Agency for Drugs and Technologies in Health; NHS: National Health Service; NICE: National Institute for Health and Care Excellence; PRESS: Peer Review of Electronic Search Strategies; PRISMA-

ScR: Preferred Reporting Items for Systematic Reviews and Meta-analyses extension for Scoping Reviews

\section{Acknowledgements}

The authors would like to acknowledge Dr. Diane Lorenzetti (University of Calgary) for his assistance on developing the electronic search strategy and Ms. Zahra Premji (University of Calgary) for peer review of the electronic search strategy.

\section{Authors' contributions}

EES contributed to study concept and design, acquisition, analysis and interpretation of data, statistical analyses, drafting of the manuscript, and critical revision of the manuscript for important intellectual content. CdG contributed to acquisition, analysis and interpretation of data, and critical revision of the manuscript for important intellectual content. FMC contributed to study concept and design, analysis and interpretation of data, and critical revision of the manuscript for important intellectual content. JPL contributed to study concept and design, analysis and interpretation of data, and critical revision of the manuscript for important intellectual content. LWB contributed to acquisition, analysis and interpretation of data, and critical revision of the manuscript for important intellectual content. HTS contributed to study concept and design, analysis and interpretation of data, drafting of the manuscript, critical revision of the manuscript for important intellectual content, and overall study supervision. DJN contributed to study concept and design, analysis and interpretation of data, statistical analyses, drafting of the manuscript, critical revision of the manuscript for important intellectual content, and overall study supervision. EES and DJN had full access to all the data in the study and take full responsibility for the integrity of the data and for the accuracy of the data analysis. DJN (corresponding author) attests that all listed authors meet the authorship criteria and that no others meeting the criteria have been omitted. All authors read and approved the final manuscript.

\section{Funding}

The funding sources (MSI Foundation, Canadian Frailty Network) were not involved in the study design, collection, analysis and interpretation of data, writing of the report, nor in the decision to submit the article for publication. The researchers were independent from funders, and all authors had full access to all of the data in the study and can take responsibility for the integrity of the data and the accuracy of the data analysis.

\section{Availability of data and materials}

All data generated or analyzed during this study are included in this published article and its supplementary information files.

Ethics approval and consent to participate Not applicable

Consent for publication

Not applicable

\section{Competing interests}

The authors declare that they have no competing interests.

\section{Author details}

'Department of Community Health Sciences, Cumming School of Medicine, University of Calgary, Calgary, Canada. ${ }^{2} \mathrm{O}^{\prime}$ Brien Institute of Public Health, Cumming School of Medicine, University of Calgary, Calgary, Canada. ${ }^{3}$ School of Health Administration, Faculty of Health, Dalhousie University, Calgary, 
Canada. ${ }^{4}$ Department of Critical Care Medicine, Cumming School of Medicine, University of Calgary and Alberta Health Services, Calgary, Canada.

\section{Received: 14 October 2019 Accepted: 23 March 2020 Published online: 07 April 2020}

\section{References}

1. Elshaug $A G$, Rosenthal MB, Lavis JN, et al. Levers for addressing medical underuse and overuse: achieving high-value health care. Lancet. 2017;390: 191-202. https://doi.org/10.1016/S0140-6736(16)32586-7.

2. Badgery-Parker T, Pearson S-A, Dunn S, et al. Measuring hospital-acquired complications associated with low-value care. JAMA Intern Med. 2019;179: 499. https://doi.org/10.1001/jamainternmed.2018.7464.

3. Korenstein D, Chimonas S, Barrow B, et al. Development of a conceptual map of negative consequences for patients of overuse of medical tests and treatments. JAMA Intern Med. 2018;178:1401-7. https://doi.org/10.1001/ jamainternmed.2018.3573.

4. Dhruva SS, Schroeder AR, Morgan DJ, et al. 2017 Update on pediatric medical overuse. JAMA Pediatr. 2018;172:482. https://doi.org/10.1001/ jamapediatrics.2017.5752.

5. Carroll AE. The high costs of unnecessary care. JAMA - J Am Med Assoc. 2017:318:1748-9. https://doi.org/10.1001/jama.2017.16193.

6. Bece A, Hamilton C, Hickey BE. Over 150 potentially low-value health care practices: an Australian study. Med J Aust. 2013;198:597-8. https://doi.org/ 10.5694/mja13.10080.

7. Prasad V, Vandross A, Toomey $C$, et al. A decade of reversal: an analysis of 146 contradicted medical practices. Mayo Clin Proc. 2013;88:790-8. https:// doi.org/10.1016/j.mayocp.2013.05.012.

8. Kerr EA, Kullgren JT, Saini SD. Choosing Wisely: How to fulfill the promise in the next 5 years. Health Aff. 2017;36:2012-8. https://doi.org/10.1377/hlthaff.2017.0953.

9. Wammes JJG, Marle ME van den A, Verkerk EW, et al. Identifying and prioritizing lower value services from Dutch specialist guidelines and a comparison with the UK do-not-do list. BMC Med. 2016;14. https://doi.org/ 10.1186/S12916-016-0747-7

10. Canadian Institute for Health Information. Unnecessary care in Canada. Ottawa, ON: 2017

11. Rosenberg A, Agiro A, Gottlieb M, et al. Early trends among seven recommendations from the Choosing Wisely Campaign. JAMA Intern Med. 2015;175:1913. https://doi.org/10.1001/jamainternmed.2015.5441.

12. Niven DJ, Rubenfeld GD, Kramer AA, et al. Effect of published scientific evidence on glycemic control in adult intensive care units. JAMA Intern Med. 2015;175:801-9. https://doi.org/10.1001/jamainternmed.2015.0157.

13. Montini T, Graham ID. "Entrenched practices and other biases": Unpacking the historical, economic, professional, and social resistance to deimplementation. Implement Sci. 2015;10:24. https://doi.org/10.1186/s13012015-0211-7.

14. Elshaug AG, Hiller JE, Tunis SR, et al. Challenges in Australian policy processes for disinvestment from existing, ineffective health care practices. Aust New Zealand Health Policy. 2007:4:23. https://doi.org/10.1186/1743 8462-4-23.

15. Norton WE, Chambers DA. Unpacking the complexities of de-implementing inappropriate health interventions. Implement Sci. 2020;15:2. https://doi.org/ 10.1186/s13012-019-0960-9

16. Born KB, Coulter A, Han A, et al. Engaging patients and the public in Choosing Wisely. BMJ Qual Saf. 2017;26:687-91. https://doi.org/10.1136/ bmjas-2017-006595.

17. Colla $\mathrm{CH}$, Mainor AJ, Hargreaves C, et al. Interventions aimed at reducing use of low-value health services: a systematic review. 2017. https://doi.org/ $10.1177 / 1077558716656970$.

18. Mackean $G$, Noseworthy $T$, Elshaug AG, et al. Health technology reassessment: the art of the possible clinical advisory and research branch Int J Technol Assess Health Care. 2018;29:418-23. https://doi.org/10.1017/ S0266462313000494

19. Harris $\mathrm{C}, \mathrm{Ko} \mathrm{H}$, Waller $\mathrm{C}$, et al. Sustainability in health care by allocating resources effectively (SHARE) 4: exploring opportunities and methods for consumer engagement in resource allocation in a local healthcare setting. BMC Health Serv Res. 2017:17:329. https:/doi.org/10.1186/s12913-017-2212-5.

20. Oren $O$, Kebebew E, loannidis JPA. Curbing unnecessary and wasted diagnostic imaging. JAMA - J Am Med Assoc. 2019;321:245-6. https://doi. org/10.1001/jama.2018.20295.
21. Brownlee $\mathrm{S}$, Berman A. Defining value in health care resource utilization: articulating the role of the patient; 2016.

22. Weiner J, Rosenquist R. Issue at the heart of advancing the de-adoption of lowvalue care. Proceedings from an expert roundtable. LDI Issue Brief. 2017:21:1-4

23. Colla $\mathrm{CH}$. Swimming against the current - what might work to reduce low-value care? N Engl J Med. 2014;371:1280-3. https://doi.org/10.1056/NEJMp1404503.

24. The Joanna Briggs Institute. The Joanna Briggs Institute Reviewers' Manual. Joanne Briggs Inst 2017;1-24. https://doi.org/10.1017/CBO9781107415324.004.

25. Garritty C, Moher D, Aldcroft A, et al. PRISMA Extension for Scoping Reviews (PRISMA-ScR): Checklist and Explanation. Ann Intern Med. 2018;169:467. https://doi.org/10.7326/m18-0850.

26. McGowan J, Sampson M, Salzwedel DM, et al. PRESS peer review of electronic search strategies: 2015 guideline statement. J Clin Epidemiol. 2016;75:40-6. https://doi.org/10.1016/j.jclinepi.2016.01.021.

27. Niven DJ, Mrklas KJ, Holodinsky JK, et al. Towards understanding the deadoption of low-value clinical practices: a scoping review. BMC Med. 2015; 13:255. https://doi.org/10.1186/s12916-015-0488-z.

28. Gnjidic D, Elshaug AG. De-adoption and its 43 related terms: Harmonizing low-value care terminology. BMC Med. 2015;13:1-3. https://doi.org/10.1186/ s12916-015-0511-4.

29. Canadian Agency for Drugs and Technologies in Health. Grey matters: a practical tool for searching health-related grey literature. 2015.https://www. cadth.ca/resources/finding-evidence/grey-matters (accessed 11 Apr 2018).

30. Landis JR, Koch GG. The measurement of observer agreement for categorical data. Biometrics. 1977;33:159. https://doi.org/10.2307/2529310.

31. Kullgren JT, Malani $P$, Kirch $M$, et al. A national survey of older americans about overuse of health care services. J Gen Intern Med. 2018;33:83-840. https://doi.org/10.1007/s11606-018-4413-y.

32. Linsky A, Simon SR, Bokhour B. Patient perceptions of proactive medication discontinuation. Patient Educ Couns. 2015;98:220-5. https://doi.org/10.1016/ j.pec.2014.11.010.

33. Hislop JM. Societal preferences for health technology disinvestment policy: views of Scottish taxpayers - a qualitative study. Value Heal. 2011;14:A3567. https://doi.org/10.1016/j.jval.2011.08.680.

34. Rohrbacher R, Marx P, Schaufler T, et al. Patient-based medicine: aligning patients' perspectives on disease and treatment with evidence-based medicine criteria. J Public Health (Bangkok). 2009;17:167-76. https://doi.org/ 10.1007/s10389-008-0213-x.

35. Schoenborn NL, Lee K, Pollack CE, et al. Older adults' views and communication preferences about cancer screening cessation. JAMA Intern Med. 2017;177:1121-8. https://doi.org/10.1001/jamainternmed.2017.1778.

36. Daniels T, Williams I, Bryan S, et al. Involving citizens in disinvestment decisions: what do health professionals think? Findings from a multimethod study in the English NHS. Heal Econ Policy Law. 2018;13:162-88. https://doi.org/10.1017/S1744133117000330

37. Kanzaria HK, Brook RH, Probst MA, et al. Emergency physician perceptions of shared decision-making. Acad Emerg Med. 2015;22:399-405. https://doi. org/10.1111/acem.12627

38. Scales K, Zimmerman S, Reed D, et al. Nurse and medical provider perspectives on antibiotic stewardship in nursing homes. J Am Geriatr Soc. 2017:65:165-71. https://doi.org/10.1111/jgs.14504.

39. Ellen ME, Perlman S. Nurses' perceptions on the overuse of health services: a qualitative study. J Nurs Scholarsh an Off Publ Sigma Theta Tau Int Honor Soc Nurs. 2018;50:219-27. https://doi.org/10.1111/jnu.12371.

40. Embrett M, Randall GE. Physician perspectives on Choosing Wisely Canada as an approach to reduce unnecessary medical care: a qualitative study. Heal Res policy Syst. 2018;16:95. https://doi.org/10.1186/s12961-018-0370-5.

41. Garner S, Littlejohns P. Disinvestment from low value clinical interventions: NICEly done? BMJ. 2011;343:d4519. https://doi.org/10.1136/bmj.d4519.

42. Cassel CK, Guest JA. Choosing Wisely. JAMA. 2012;307:1801. https://doi.org/ 10.1001/jama.2012.476

43. Zikmund-Fisher BJ, Kullgren JT, Fagerlin A, et al. Perceived barriers to implementing individual Choosing Wisely ${ }^{\circledR}$ Recommendations in two national surveys of primary care providers. J Gen Intern Med. 2017:32:210-7. https://doi.org/10.1007/s11606-016-3853-5.

44. O'Malley AS, Collins A, Contreary K, et al. Barriers to and facilitators of evidence-based decision making at the point of care. MDM Policy Pract. 2016:1:238146831666037. https://doi.org/10.1177/2381468316660375.

45. Fenton JJ, Franks P, Feldman MD, et al. Impact of patient requests on provider-perceived visit difficulty in primary care. J Gen Intern Med. 2014:30: 214-20. https://doi.org/10.1007/s11606-014-3082-8. 
46. Silverstein W, Lass E, Born $\mathrm{K}$, et al. A survey of primary care patients' readiness to engage in the de-adoption practices recommended by Choosing Wisely Canada. BMC Res Notes. 2016;9:1-8. https://doi.org/10. 1186/s13104-016-2103-6.

47. Bansback N, Chiu J, Kerr S, et al. Reducing imaging tests for low back pain: can patients choose wisely? Arthritis Rheumatol. 2016;68.

48. Nuffield Council on Bioethics. Public health: ethical issues. London: 2017.

49. Elwyn G, Frosch D, Thomson R, et al. Shared decision making: a model for clinical practice. J Gen Intern Med. 2012;27:1361-7. https://doi.org/10.1007/ s11606-012-2077-6.

50. Stacey D, Légaré $F$, Lewis $K$, et al. Decision aids for people facing health treatment or screening decisions. Cochrane Database Syst Rev. 2017;2017: CD001431. https://doi.org/10.1002/14651858.CD001431.pub5.

51. Brenner AT, Malo TL, Margolis M, et al. Evaluating shared decision making for lung cancer screening. JAMA Intern Med. 2018;178:1311. https://doi.org/ 10.1001/jamainternmed.2018.3054.

52. Scheunemann $L P$, Ernecoff $N C$, Buddadhumaruk $P$, et al. Clinician-family communication about patients' values and preferences in intensive care units. JAMA Intern Med Published Online First: 1 April 2019. https://doi.org/ 10.1001/jamainternmed.2019.0027.

53. Haesebaert J, Adekpedjou R, Croteau J, et al. Shared decision-making experienced by Canadians facing health care decisions: a Web-based survey. C Open. 2019;7:E210-6. https://doi.org/10.9778/cmajo.20180202.

54. Joseph-Williams N, Lloyd A, Edwards A, et al. Implementing shared decision making in the NHS: lessons from the MAGIC programme. BMJ. 2017;357: j1744. https://doi.org/10.1136/bmi.j1744.

55. Hodgetts K, Hiller JE, Street JM, et al. Disinvestment policy and the public funding of assisted reproductive technologies: outcomes of deliberative engagements with three key stakeholder groups. BMC Health Serv Res. 2014;14:204. https://doi.org/10.1186/1472-6963-14-204.

56. Street JM, Callaghan P, Braunack-Mayer AJ, et al. Citizens' perspectives on disinvestment from publicly funded pathology tests: a deliberative forum. Value Heal. 2015;18:1050-6. https://doi.org/10.1016/j.jval.2015.05.012.

57. Litva A, Coast J, Donovan J, et al. "The public is too subjective": public involvement at different levels of health-care decision making. Soc Sci Med. 2002;54:1825-37.

58. Mitton C, Smith N, Peacock S, et al. Public participation in health care priority setting: A scoping review. Health Policy (New York). 2009;91:219-28. https://doi.org/10.1016/..healthpol.2009.01.005.

59. Manafo E, Petermann L, Mason-Lai P, et al. Patient engagement in Canada: a scoping review of the 'how' and 'what' of patient engagement in health research. Heal Res Policy Syst. 2018;16:5. https://doi.org/10.1186/s12961-0180282-4.

60. Brett J, Staniszewska S, Mockford C, et al. Mapping the impact of patient and public involvement on health and social care research: a systematic review. Heal Expect. 2014;17:637-50. https://doi.org/10.1111/j.1369-7625. 2012.00795.x.

\section{Publisher's Note}

Springer Nature remains neutral with regard to jurisdictional claims in published maps and institutional affiliations.

Ready to submit your research? Choose BMC and benefit from:

- fast, convenient online submission

- thorough peer review by experienced researchers in your field

- rapid publication on acceptance

- support for research data, including large and complex data types

- gold Open Access which fosters wider collaboration and increased citations

- maximum visibility for your research: over $100 \mathrm{M}$ website views per year

At $\mathrm{BMC}$, research is always in progress.

Learn more biomedcentral.com/submissions 